Check for updates

Cite this: RSC Adv., 2017, 7, 34293

\title{
Mono and double Mizoroki-Heck reaction of aryl halides with dialkyl vinylphosphonates using a reusable palladium catalyst under aqueous medium $\dagger$
}

\begin{abstract}
Han-Sheng Lee, Shao-Hsuan Pai, Wei-Ting Liao, Xin-Jing Yang and Fu-Yu Tsai (DD *
Operationally-simple and reusable Pd-catalyzed mono and double Mizoroki-Heck reactions of aryl halides and dialkyl vinylphosphonates using ${ }^{i} \mathrm{Pr}_{2} \mathrm{NH}$ as a base in aqueous medium under air were developed. For aryl iodides, the reaction could be conducted at $80^{\circ} \mathrm{C}$ under a low catalyst loading $(0.1-1 \mathrm{~mol} \%)$. When aryl bromides were applied, however, a greater amount of catalyst $(5 \mathrm{~mol} \%)$ and a longer reaction time at $120{ }^{\circ} \mathrm{C}$ were required. Simply changing dialkyl vinylphosphonates as the limiting reagent led to the formation of 2,2-diaryl vinylphosphonates in good to high yields. After reaction, the residual aqueous solution could be reused for both mono and double Mizoroki-Heck reactions, making the reactions greener and reducing wastage of precious metals and use of harmful organic solvents as the reaction

medium.
\end{abstract}

Received 9th June 2017

Accepted 30th June 2017

DOI: $10.1039 / \mathrm{c} 7 \mathrm{ra0} 6464 \mathrm{k}$

rsc.li/rsc-advances

\section{Introduction}

Alkenylphosphonates are important molecules that have been widely applied in organic synthesis, ${ }^{1-14}$ materials science, ${ }^{15-17}$ medical chemistry, ${ }^{18-21}$ and as polymer additives ${ }^{22}$ and flame retardants. ${ }^{23,24}$ Transition-metal-catalyzed reactions for the formation of alkenylphosphonates mainly include crosscoupling of $\mathrm{P}(\mathrm{O}) \mathrm{H}$ with vinyl halides or pseudo halides, ${ }^{25-40}$ olefin cross-metathesis, ${ }^{41}$ reaction of $\mathrm{HP}(\mathrm{O})$ compounds with alkynes $^{42-50}$ or alkenes, ${ }^{51,52}$ Suzuki-Miyaura coupling of boronic acids with vinylphosphonates, ${ }^{53-59}$ and Mizoroki-Heck reaction of vinylphosphonates with various aryl partners. ${ }^{60-66}$ Although diverse methods have been used and impressive results obtained for the aforementioned reactions, most methods of such catalytic reactions use harmful organic solvents, such as $\mathrm{CH}_{2} \mathrm{Cl}_{2}$, toluene, and DMF, as the reaction medium. It would therefore be highly valuable to develop a transition-metalcatalyzed reaction for the synthesis of alkenylphosphonates that does not employ an organic solvent as the reaction medium. The introduction of neat water as the reaction medium possesses several advantages, including a low cost, nontoxicity, non-flammable nature, and easy separation from the organic products and reuse of water-soluble catalysts. ${ }^{67-84}$

Institute of Organic and Polymeric Materials, National Taipei University of Technology, 1, Sec. 3, Chung-Hsiao E. Rd., Taipei 10608, Taiwan.E-mail: fuyutsai@ ntut.edu.tw

$\dagger$ Electronic supplementary information (ESI) available: Spectroscopic characterization data of all mono and double Mizoroki-Heck products; HRMS data; copies of ${ }^{1} \mathrm{H},{ }^{13} \mathrm{C}$, and ${ }^{31} \mathrm{P}$ NMR spectra for unknown compounds. See DOI: $10.1039 / \mathrm{c} 7 \mathrm{ra} 06464 \mathrm{k}$
Although heterogeneous supported palladium catalysts have been applied to study recyclability, harmful DMF was employed as the reaction medium. ${ }^{64}$

On the other hand, transition-metal-catalyzed cross-coupling for the formation of 2,2-diaryl vinylphosphonates is rare. Known procedures include phosphorylation of 1,1-diarylethene by $\mathrm{Ag}^{51,85}$ or $\mathrm{Cu},{ }^{26,27,86}$ arylzincation of alkynylphosphonates by $\mathrm{Co}^{87} \mathrm{Negishi}$ coupling using vinylic tellurides, ${ }^{88}$ arylation of alkynylphosphonates with aryl halides or arylboronic acids, ${ }^{53,89,90}$ and HUSY zeolite-promoted hydrophenylation of diethyl (2-phenylethynyl) phosphonate with benzene. ${ }^{91}$ However, the coupling of aryl halides and vinylphosphonates via a double Mizoroki-Heck reaction has not yet been explored.

In this study, we developed a green and operationally-simple palladium-catalyzed procedure to synthesize 2-aryl and 2,2diaryl vinylphosphonates using water as the reaction medium under aerobic conditions. The use of aryl halides as the limiting reagent produces mono Mizoroki-Heck products; on the contrary, double Mizoroki-Heck products are selectively formed when vinylphosphonate plays the role of limiting reagent (Scheme 1). Moreover, the reusability of the residual aqueous solution for these two kinds of reaction was also examined.

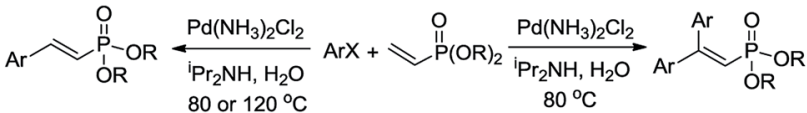

$$
\begin{aligned}
& \mathrm{X}=\mathrm{I}, \mathrm{Br} ; \mathrm{R}=\mathrm{Et},{ }^{i} \mathrm{Pr} \\
& \operatorname{ArX} \text { is limiting reagent } \\
& \mathrm{X}=\mathrm{I} ; \mathrm{R}=\mathrm{Et},{ }^{i} \mathrm{Pr} \\
& \text { Vinylphosphonate is limiting reagent }
\end{aligned}
$$

Scheme 1 Pd-catalyzed mono and double Mizoroki-Heck reactions in water. 


\section{Results and discussion}

In previous studies, we found that ${ }^{i} \mathrm{Pr}_{2} \mathrm{NH}$ is the best base to employ for the coupling of aryl halides and dialkyl allylphosphonates; ${ }^{92}$ therefore, it was also used as the base in the Mizoroki-Heck reaction of aryl halides and dialkyl vinylphosphonate. As shown in Table 1, iodobenzene $1 \mathrm{a}(1 \mathrm{mmol})$, diethyl vinylphosphonate $2 \mathrm{a}(2 \mathrm{mmol}),{ }^{i} \mathrm{Pr}_{2} \mathrm{NH}(1.1 \mathrm{mmol})$, and $\mathrm{PdCl}_{2}\left(\mathrm{NH}_{3}\right)_{2}(5 \mathrm{~mol} \%)$ were reacted in an open-air reactor at $80{ }^{\circ} \mathrm{C}$ using water $(3 \mathrm{~mL})$ as the solvent. Under such conditions, 3a was obtained in a near-quantitative yield within $24 \mathrm{~h}$ (Entry 1). In order to optimize the conditions, reducing the catalyst loading to $1 \mathrm{~mol} \%$ afforded 3a in a $98 \%$ isolated yield (Entry 2). Upon investigation of the reaction time, it was found that $6 \mathrm{~h}$ was sufficient for the reaction to reach completion, indicating the high efficiency of this catalytic system (Entries 3-5). With an auxiliary water-soluble cationic 2,2'-bipyridyl ligand, ${ }^{93}$ a $99 \%$ product yield was achieved under conditions identical to those for Entry 4 (Entry 6). The results showed that the water-soluble cationic 2,2'-bipyridyl ligand may be not crucial in the coupling reaction. Use of this catalyst without an auxiliary ligand to fulfill the Mizoroki-Heck reaction has been described previously, in which Pd nanoparticles were formed during the coupling reaction. ${ }^{92}$ The reaction rates of vinylphosphonates were faster than those of allylphosphonates, which may be due to the electron-withdrawing phosphonate group of 2 a becoming attached directly to the vinyl carbon, which lowers the $\pi^{*}$ energy level of the olefin, facilitating coordination of the $\pi$ bond to palladium. Then, the catalyst loading was further reduced to 0.1 mol\%, resulting in $68 \%$ and $70 \%$ product yields, respectively, with a prolonged reaction time (Entries 7 and 8). When 2a was

Table 1 Optimization of palladium-catalyzed Mizoroki-Heck reaction of $1 \mathrm{a}$ and $2 \mathrm{a}$ in water $^{a}$

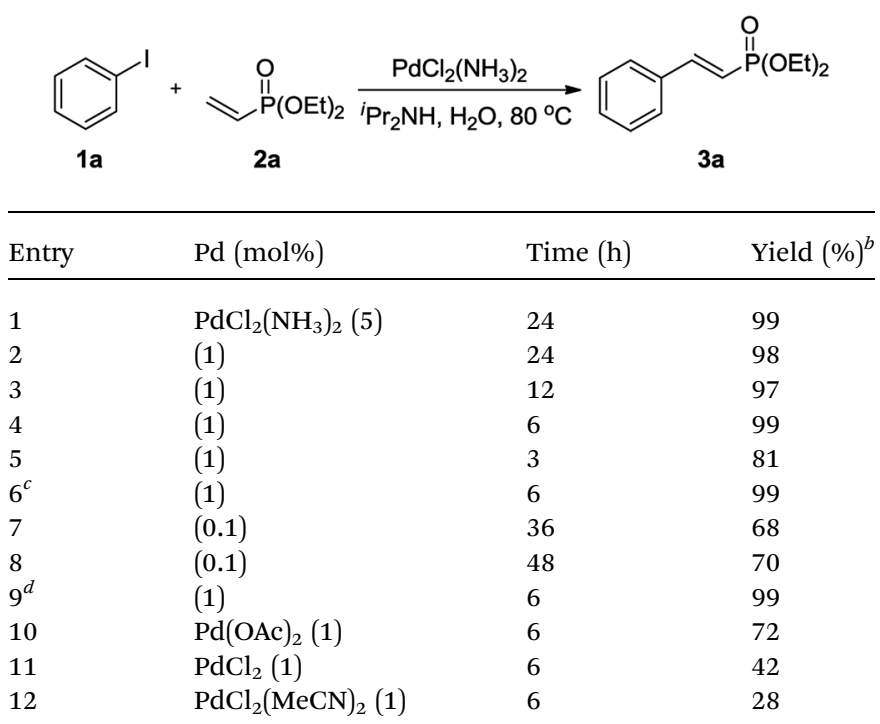

${ }^{a}$ Reaction conditions: 1a $(1.0 \mathrm{mmol}), 2 \mathrm{a}(2.0 \mathrm{mmol}){ }^{i} \mathrm{Pr}_{2} \mathrm{NH}(1.1 \mathrm{mmol})$, $\mathrm{PdCl}_{2}\left(\mathrm{NH}_{3}\right)_{2}$, and $\mathrm{H}_{2} \mathrm{O}(3 \mathrm{~mL})$ at $80{ }^{\circ} \mathrm{C}$ under air. ${ }^{b}$ Isolated yields. ${ }^{c}$ Cationic 2,2'-bipyridyl was used as the ligand. ${ }^{d}$ Diisopropyl vinylphosphonate (2b) was used as the reactant. replaced by diisopropyl vinylphosphonate, $\mathbf{2} \mathbf{b}$, a near quantitative yield of $\mathbf{4 a}$ was also delivered under the conditions of Entry 4 (Entry 9). Other commonly-used palladium salts were also examined; however, the product yields were much lower than those obtained with $\mathrm{PdCl}_{2}\left(\mathrm{NH}_{3}\right)_{2}$ (Entries 10-12). Therefore, reaction with $1 \mathrm{~mol} \% \mathrm{PdCl}_{2}\left(\mathrm{NH}_{3}\right)_{2}$ in the absence of an auxiliary ligand (Entry 4) was chosen as the optimal condition.

Following optimization of the reaction conditions (Table 1, Entry 4), a variety of aryl iodides 1 were reacted with 2 in order to explore the scope of this catalytic system. As shown in Table 2, electron-rich aryl iodides $\mathbf{1 b}$ and $\mathbf{1 c}$ were arylated to $\mathbf{2}$ smoothly, delivering the corresponding products in high yields (Entries 1 and 2). With electron-deficient aryl iodides, for instance $\mathbf{1 d - j}$, the reactions took place very efficiently, and the desired products $\mathbf{3 d}-\mathbf{j}$ and $\mathbf{4 d} \mathbf{d}-\mathbf{j}$ were obtained in excellent yields (Entries 39). Sterically-congested $\mathbf{1 k}-\mathbf{m}$ did not affect the reaction, and excellent product yields were achieved (Entries 10-12). 3Substituted aryl iodides 1n-p, without an electronic effect on the aromatic ring, were able to be applied as reactants to couple with 2, providing the desired products $3 \mathbf{n}-\mathbf{p}$ and $\mathbf{4 n}-\mathbf{p}$ in excellent yields (Entries 13-15).

The oxidative addition of aryl bromides to palladium is more difficult than that of iodides. So, increases of the reaction temperature and catalyst loading were required to achieve the coupling reaction when aryl bromides were employed. As illustrated in Table 3, Mizoroki-Heck reaction of 5a and 2 with 5 mol\% $\mathrm{PdCl}_{2}\left(\mathrm{NH}_{3}\right)_{2}$ at $120{ }^{\circ} \mathrm{C}$ in a sealable tube for $36 \mathrm{~h}$ led to the formation of 3a and $4 \mathrm{a}$ in $68 \%$ and $69 \%$ yields, respectively (Entry 1). Coupling of electron-rich aryl bromides $5 \mathbf{b}-\mathbf{c}$ with 2 (Entries 2 and 3) was much slower than with electron-poor $\mathbf{5 d - j}$ (Entries 4-9). A steric effect on 2-substituted aryl bromides was apparent; therefore, coupling of 5k-m with 2 gave the target products in yields of between $35 \%$ and $61 \%$, respectively (Entries 10-12). For 3-substituted aryl bromides, such as $\mathbf{5 n - p}$, the products were given in yields comparable with those produced using 5a (Entries 13-15).

When the limiting reagent was changed from aryl halides to vinylphosphonates, we were pleased to find that double Mizoroki-Heck products could be selectively obtained (Table 4). Under a lower catalyst loading, the reaction gave only a $47 \%$ yield of $6 \mathbf{a}$ when conducted at $80{ }^{\circ} \mathrm{C}$ for $48 \mathrm{~h}$ (Entry 1). Further increasing the catalyst loading to $5 \mathrm{~mol} \%$ was required to obtain a satisfactory outcome (Entry 2). Both electron-rich and -deficient aryl iodides were able to couple with 2 , giving the desired products in good to high yields (Entries 3-6). However, low yields were furnished when the trifluoromethyl group was located at the para position (Entry 7). It was known that 4substituted aryl iodides with strong electron-withdrawing functional groups such as $\mathrm{NO}_{2}$ - and $\mathrm{CF}_{3}$-render the double Mizoroki-Heck reaction inert. ${ }^{94}$ Sterically-congested aryl iodides, such as $\mathbf{1} \mathbf{k}$ and $\mathbf{1 l}$, were transformed efficiently to the corresponding 2,2-diaryl vinylphosphonates in higher yields, indicating that the steric effect did not hinder this double Mizoroki-Heck reaction (Entries 8 and 9). 3-Substituted aryl iodides $1 \mathbf{n}-\mathbf{1 p}$ were also well-tolerated under such conditions, which provided the corresponding double Mizoroki-Heck products in good to high yields (Entries 10-12). 
Table 2 Pd-catalyzed monoarylation of aryl iodides 1 to dialkyl vinylphosphonate 2 in water ${ }^{a}$

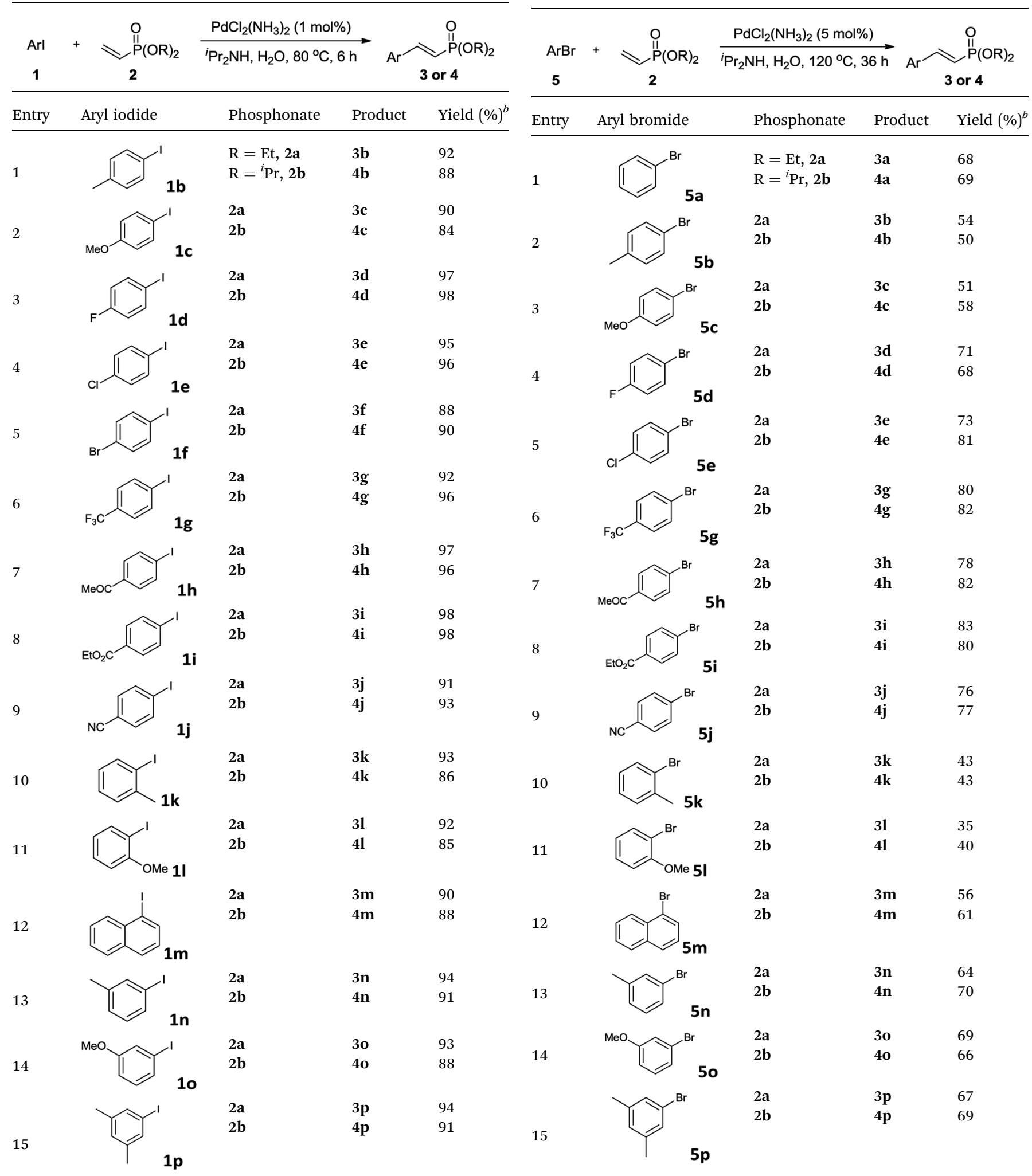

Table 3 Pd-catalyzed monoarylation of aryl bromides 5 to dialkyl vinylphosphonate 2 in water $^{a}$

${ }^{a}$ Reaction conditions: 5 (1.0 mmol), 2 (2.0 mmol), $\operatorname{PdCl}_{2}\left(\mathrm{NH}_{3}\right)_{2}(5$ mol\%) ${ }^{i} \mathrm{Pr}_{2} \mathrm{NH}(1.1 \mathrm{mmol})$, and $\mathrm{H}_{2} \mathrm{O}(3 \mathrm{~mL})$ at $120{ }^{\circ} \mathrm{C}$ for $36 \mathrm{~h}$. ${ }^{b}$ Isolated yields.
${ }^{a}$ Reaction conditions: 1 (1.0 mmol), 2 (2.0 mmol), $\mathrm{PdCl}_{2}\left(\mathrm{NH}_{3}\right)_{2}$ (1 $\mathrm{mol} \%){ }^{i} \mathrm{Pr}_{2} \mathrm{NH}(1.1 \mathrm{mmol})$, and $\mathrm{H}_{2} \mathrm{O}(3 \mathrm{~mL})$ at $80{ }^{\circ} \mathrm{C}$ for $6 \mathrm{~h} .{ }^{b}$ Isolated yields. 
Table 4 Pd-catalyzed double arylation of aryl iodides 1 to dialkyl vinylphosphonate 2 in water $^{a}$

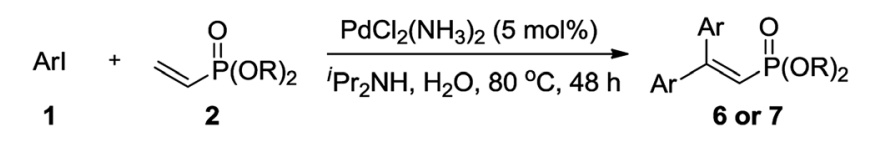

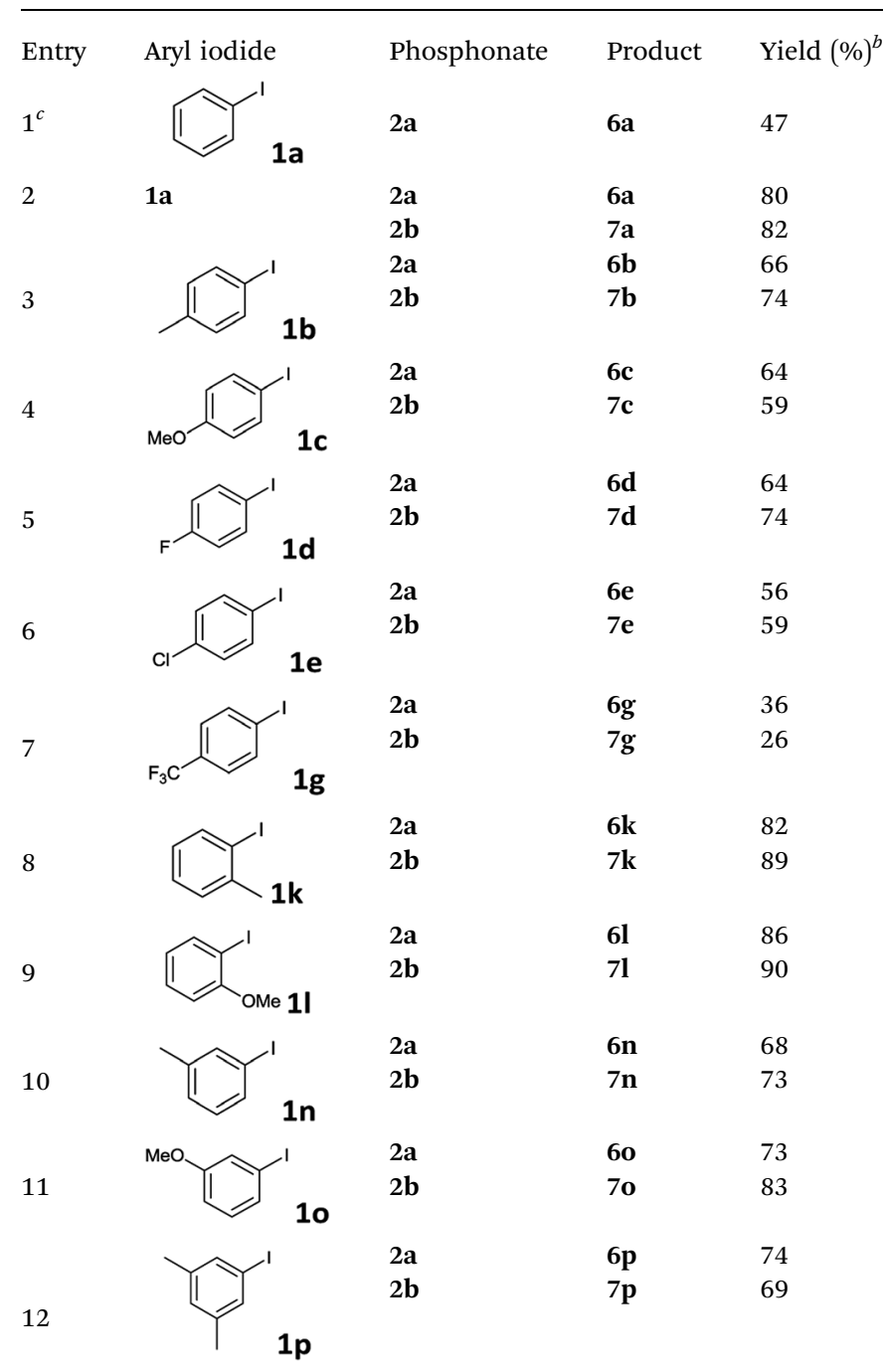

${ }^{a}$ Reaction conditions: 1 (2.5 mmol), 2 (1.0 mmol), $\mathrm{PdCl}_{2}\left(\mathrm{NH}_{3}\right)_{2}(5$ mol\%) ${ }^{i} \mathrm{Pr}_{2} \mathrm{NH}(2.5 \mathrm{mmol})$, and $\mathrm{H}_{2} \mathrm{O}(3 \mathrm{~mL})$ at $80{ }^{\circ} \mathrm{C}$ for $48 \mathrm{~h}$. ${ }^{b}$ Isolated yields. ${ }^{c} 1 \mathrm{~mol} \%$ of $\mathrm{PdCl}_{2}\left(\mathrm{NH}_{3}\right)_{2}$ was used.

The proposed mechanism for both mono and double Mizoroki-Heck reactions was shown in Scheme 2. After the oxidative addition of an aryl halide to $\operatorname{Pd}(0)$ nanoparticles, coordination of a dialkyl vinylphosphonate to $\mathrm{Pd}(\mathrm{II})$ and subsequent migratory insertion of the aryl group occurred. The following $\beta$-hydride elimination delivered a mono MizorokiHeck product along with palladium hydride, which was neutralized by a base to regenerate $\operatorname{Pd}(0)$ nanoparticles. With regard to the double Mizoroki-Heck reaction, the produced mono Mizoroki-Heck product in the first cycle acted as the alkene for the $\mathrm{Pd}(\mathrm{II})$ coordination. After migratory insertion and

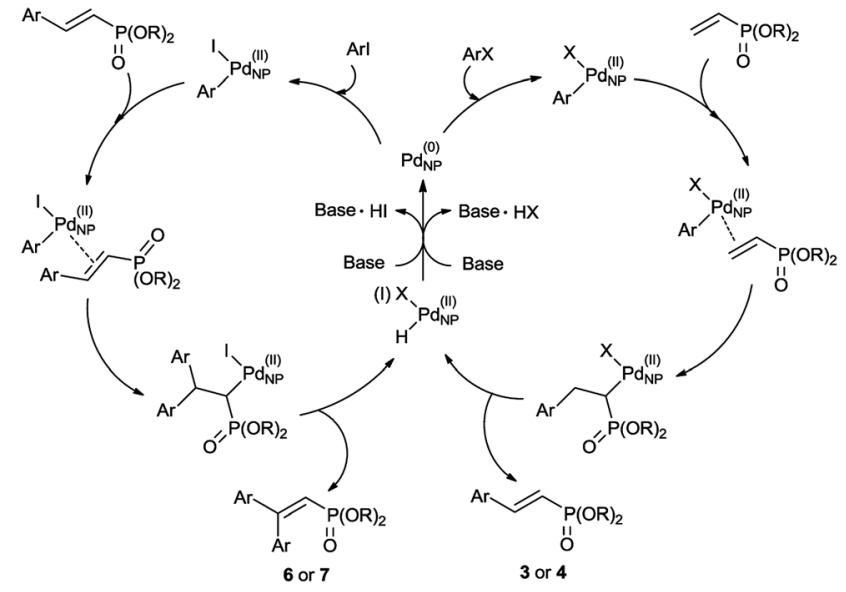

Scheme 2 Proposed mechanism for the mono and double MizorokiHeck reaction.

$\beta$-hydride elimination, the double Mizoroki-Heck product was afforded.

On the basis of the broad scope of this catalytic reaction, the reusability of the aqueous catalytic solution was then examined, and the results are summarized in Table 5. Under conditions identical to those described in Table 2, Entry 4, after the initial reaction of $\mathbf{1 e}$ and $\mathbf{2 a}$, the reaction mixture was extracted with ethyl acetate $(3 \times 3 \mathrm{~mL})$ and $3 \mathbf{e}$ was purified by column chromatography. The remaining aqueous solution was then charged with 1e, $\mathbf{2 a}$, and base for the reuse run. Only slightly decreased product yields were obtained in the reuse runs (Entry 1). When 5i was employed, we found that the catalytic activity decayed quickly, and the formation of palladium black on the glass reactor was observed due to the higher reaction temperature (Entry 2). ${ }^{\mathbf{9}}$ In reuse studies for the double Mizoroki-Heck reaction, 1p and 2a were chosen as the representative reactants. After extracting with ethyl acetate (3 $\times 3 \mathrm{~mL}$ ), a $54 \%$ isolated yield of $6 \mathbf{p}$ could be still achieved in the second reuse run (Entry 3). This operationally-simple procedure therefore provides opportunities to reduce wastage of precious metals and decrease use of harmful organic solvents as the reaction medium, and meets the criteria of green chemistry.

Table 5 Reuse studies of aryl halides and $2 a$ for mono and double Mizoroki-Heck reactions ${ }^{a}$

\begin{tabular}{llllll}
\hline & & \multicolumn{3}{c}{ Yield $(\%)^{b}$} \\
\cline { 4 - 6 } Entry & ArX & Product & Initial run & 1st reuse & 2nd reuse \\
\hline 1 & $\mathbf{1 e}$ & $\mathbf{3 e}$ & 95 & 88 & 76 \\
2 & $\mathbf{5 i}$ & $\mathbf{3 i}$ & 83 & 68 & 23 \\
3 & $\mathbf{1 p}$ & $\mathbf{6 p}$ & 74 & 63 & 54
\end{tabular}

${ }^{a}$ Reaction conditions: ArX ( $1 \mathrm{mmol}$ for Entries 1 and 2, $2.5 \mathrm{mmol}$ for Entry 3), 2a (2 mmol for Entries 1 and 2, $1 \mathrm{mmol}$ for Entry 3), $\mathrm{PdCl}_{2}\left(\mathrm{NH}_{3}\right)_{2}(1 \mathrm{~mol} \% \text { for Entry } 1,5 \mathrm{~mol} \% \text { for Entries } 2 \text { and } 3)^{i} \mathrm{Pr}_{2} \mathrm{NH}$ $\left(1.1 \mathrm{mmol}\right.$ for Entries 1 and 2, $2.5 \mathrm{mmol}$ for Entry 3), and $\mathrm{H}_{2} \mathrm{O}(3 \mathrm{~mL})$ at $80{ }^{\circ} \mathrm{C}$ (Entries 1 and 3) or $120{ }^{\circ} \mathrm{C}$ (Entry 2). ${ }^{b}$ Isolated yields. 


\section{Experimental}

\section{General information}

Chemicals were purchased from commercial suppliers and were used without further purification. 2b was synthesized according to the published procedure using $\mathrm{P}\left(\mathrm{O}^{i} \mathrm{Pr}\right)_{3}$ as the starting material. ${ }^{95}$ All ${ }^{1} \mathrm{H}$ and ${ }^{13} \mathrm{C}$ NMR spectra were recorded in $\mathrm{CDCl}_{3}$ at $25{ }^{\circ} \mathrm{C}$ on a Bruker $300 \mathrm{NMR}$ spectrometer, where chemical shifts ( $\delta$ in ppm) were determined with respect to the nondeuterated solvent as a reference $\left({ }^{1} \mathrm{H}\right.$ NMR: $\mathrm{CHCl}_{3}$ at $7.24 \mathrm{ppm} ;{ }^{13} \mathrm{C}$ NMR: $\mathrm{CDCl}_{3}$ at $\left.77.0 \mathrm{ppm}\right) .{ }^{31} \mathrm{P} \mathrm{NMR}$ spectra for unknown compounds were recorded in $\mathrm{CDCl}_{3}$ at $25{ }^{\circ} \mathrm{C}$ on a Varian $400 \mathrm{NMR}$ spectrometer using $85 \% \mathrm{H}_{3} \mathrm{PO}_{4}$ as an external standard. Melting points were recorded using melting point apparatus and were uncorrected. HRMS for unknown compounds were recorded at the Instrument Center Service of National Central University, Ministry of Science and Technology of Taiwan. All known products obtained were pure, and their spectra $\left({ }^{1} \mathrm{H}\right.$ and $\left.{ }^{13} \mathrm{C} \mathrm{NMR}\right)$ were in agreement with those of authentic samples (see the ESI $\dagger$ for the spectral data of all mono and double Mizoroki-Heck products).

\section{Typical procedure for the mono Mizoroki-Heck reaction}

In a $25 \mathrm{~mL}$ reaction tube, $\mathrm{PdCl}_{2}\left(\mathrm{NH}_{3}\right)_{2}(1 \mathrm{~mol} \%$ for 1 or $5 \mathrm{~mol} \%$ for 5) was added to $\mathrm{H}_{2} \mathrm{O}(3 \mathrm{~mL})$ and the solution was stirred at room temperature for $10 \mathrm{~min}$. The tube was then charged with 1 or 5 (1.0 mmol), $2(2.0 \mathrm{mmol})$, and ${ }^{i} \mathrm{Pr}_{2} \mathrm{NH}(1.1 \mathrm{mmol})$ and stirred at $80{ }^{\circ} \mathrm{C}$ for $6 \mathrm{~h}$ or $120{ }^{\circ} \mathrm{C}$ (for which a sealable tube was used) for $36 \mathrm{~h}$. After cooling the reaction to room temperature, the resulting mixture was extracted with EtOAc $(3 \times 3 \mathrm{~mL})$. The combined organic phase was dried over $\mathrm{MgSO}_{4}$, and the solvent was then removed under vacuum. Column chromatography on silica gel (hexane/EtOAc $=1 / 9$ ) afforded the desired product.

\section{Typical procedure for the double Mizoroki-Heck reaction}

In a $25 \mathrm{~mL}$ reaction tube, $\mathrm{PdCl}_{2}\left(\mathrm{NH}_{3}\right)_{2}(5 \mathrm{~mol} \%)$ was added to $\mathrm{H}_{2} \mathrm{O}(3 \mathrm{~mL})$ and the solution was stirred at room temperature for $10 \mathrm{~min}$. The tube was then charged with 1 ( $2.5 \mathrm{mmol}), 2$ $(1.0 \mathrm{mmol})$, and ${ }^{i} \mathrm{Pr}_{2} \mathrm{NH}(2.5 \mathrm{mmol})$ and stirred at $80{ }^{\circ} \mathrm{C}$ for $48 \mathrm{~h}$. After cooling the reaction to room temperature, the resulting mixture was extracted with EtOAc $(3 \times 3 \mathrm{~mL})$. The combined organic phase was dried over $\mathrm{MgSO}_{4}$, and the solvent was then removed under vacuum. Column chromatography on silica gel (hexane/EtOAc $=1 / 9$ ) gave the desired product.

\section{Typical procedure for reuse of the residual aqueous solution for mono and double Mizoroki-Heck reactions}

The reaction was conducted following the previously-described procedure. After reaction, the aqueous reaction mixture was extracted three times with EtOAc $(3 \mathrm{~mL})$ under vigorous stirring, and the organic product was isolated from the combined organic phase according to the previously-described procedure. The residual aqueous solution was then charged with 1 or 5, 2, and ${ }^{i} \mathrm{Pr}_{2} \mathrm{NH}$ for the next run.

\section{Conclusions}

In conclusion, we have successfully developed an operationallysimple and environmentally-benign Pd-catalyzed reaction for mono and double Mizoroki-Heck arylation of aryl halides and dialkyl vinylphosphonates using the greenest solvent, water, as the reaction medium under air. 2-Arylvinylphosphonates or 2,2diarylvinylphosphonates can be selectively obtained by simply employing aryl halides or dialkyl vinylphosphonates as the limiting reagent. In addition, although the employment of aryl bromide showed poor reusability, the residual aqueous solution can be reused several times, making the reaction greener and greatly reduces the wastage of precious metals and use of harmful organic solvents.

\section{Acknowledgements}

This research was financially supported by the Ministry of Science and Technology of Taiwan (MOST 105-2113-M-027-004). We thank Prof. Yi-Tsu Chan (National Taiwan University) for obtaining the ${ }^{31} \mathrm{P}$ NMR spectra.

\section{References}

1 I. P. Beletskaya and M. A. Kazankova, Russ. J. Org. Chem., 2002, 38, 1391.

2 F. Alonso, I. P. Beletskaya and M. Yus, Chem. Rev., 2004, 104, 3079.

3 A. L. Schwan, Chem. Soc. Rev., 2004, 33, 218.

4 D. Leca, L. Fensterbank, E. Lacôte and M. Malacria, Chem. Soc. Rev., 2005, 34, 858.

5 S. Marque and P. Tordo, Top. Curr. Chem., 2005, 250, 43.

6 O. Delacroix and A. C. Gaumont, Curr. Org. Chem., 2005, 9, 1851.

7 S. N. Arbuzova, N. K. Gusarova and B. A. Trofimov, ARKIVOC, 2006, 12.

8 L. Coudray and J. L. Montchamp, Eur. J. Org. Chem., 2008, 3601.

9 S. Van der Jeught and C. V. Stevens, Chem. Rev., 2009, 109, 2672.

10 T. Janecki, J. Kędzia and T. Wąsek, Synthesis, 2009, 1227.

11 D. S. Glueck, Top. Organomet. Chem., 2010, 31, 65.

12 F. M. J. Tappe, V. T. Trepohl and M. Oestreich, Synthesis, 2010, 3037.

13 D. Zhao and R. Wang, Chem. Soc. Rev., 2012, 41, 2095.

14 H. Yorimitsu, Beilstein J. Org. Chem., 2013, 9, 1269.

15 H. Steininger, M. Schuster, K. D. Kreuer, A. Kaltbeitzel, B. Bingol, W. H. Meyer, S. Schauff, G. Brunklaus, J. Maier and H. W. Spiess, Phys. Chem. Chem. Phys., 2007, 9, 1764.

16 S. Kirumakki, J. Huang, A. Subbiah, J. Yao, A. Rowland, B. Smith, A. Mukherjee, S. Samarajeewa and A. Clearfield, J. Mater. Chem., 2009, 19, 2593.

17 V. Spampinato, N. Tuccitto, S. Quici, V. Calabrese, G. Marletta, A. Torrisi and A. Licciardello, Langmuir, 2010, 26, 8400 .

18 T. Minami and J. Motoyoshiya, Synthesis, 1992, 333. 
19 H. B. Lazrek, A. Rochdi, H. Khaider, J.-L. Barascut, J.-L. Imbach, J. Balzrini, M. Witvrouw, C. Pannecouque and E. De Clercq, Tetrahedron, 1998, 54, 3807.

20 P. Page, C. Blonski and J. Perie, Eur. J. Org. Chem., 1999, 2853.

21 D. L. Jakeman, A. J. Ivory, M. P. Williamson and G. M. Blackburn, J. Med. Chem., 1998, 41, 4439.

22 S. Jin and K. E. Gonsalves, Macromolecules, 1998, 31, 1010.

23 G. A. Russell, C.-F. Yao, H. I. Tashtoush, J. E. Russell and D. F. Dedolph, J. Org. Chem., 1991, 56, 663.

24 M. Ruiz, M. C. Fernandez, S. Conde, A. Diaz and J. M. Quintela, Synlett, 1999, 1903.

25 S. Thielges, P. Bisseret and J. Eustache, Org. Lett., 2005, 7, 681.

26 G. Evano, K. Tadiparthi and F. Couty, Chem. Commun., 2011, 47, 179.

27 K. Jouvin, A. Coste, A. Bayle, F. Legrand, G. Karthikeyan, K. Tadiparthi and G. Evano, Organometallics, 2012, 31, 7933.

28 L. Liu, Y. Wang, Z. Zeng, P. Xu, Y. Gao, Y. Yin and Y. Zhao, Adv. Synth. Catal., 2013, 355, 659.

29 Y. Wu, L. Liu, K. Yan, P. Xu, Y. Gao and Y. Zhao, J. Org. Chem., 2014, 79, 8118.

30 L. Liu, Y. Lv, Y. Wu, X. Gao, Z. Zeng, Y. Gao, G. Tang and Y. Zhao, RSC Adv., 2014, 4, 2322.

31 J.-F. Xue, S.-F. Zhou, Y.-Y. Liu, X. Pan, J.-P. Zou and O. T. Asekun, Org. Biomol. Chem., 2015, 13, 4896.

32 D. A. Holt and J. M. Erb, Tetrahedron Lett., 1989, 30, 5393.

33 M. A. Kazankova, I. G. Trostyanskaya, S. V. Lutsenko and I. P. Beletskaya, Tetrahedron Lett., 1999, 40, 569.

34 T. Okuchi, T. Yano, T. Fukamachi, J. Ichikawa and T. Minami, Tetrahedron Lett., 1999, 40, 5337.

35 P. Zhong, Z. X. Xiong and X. Huang, Synth. Commun., 2000, 30, 273.

36 T. Hirao, T. Masunaga, Y. Ohshiro and T. Agawa, Tetrahedron Lett., 1980, 21, 3595.

37 N. B. Karlstedt, M. V. Anokhin and I. P. Beletskaya, Russ. Chem. Bull., Int. Ed., 2013, 62, 2498.

38 T. Ogawa, N. Usuki and N. Ono, J. Chem. Soc., Perkin Trans. 1, 1998, 2953.

39 T. Hirao, T. Masunaga, N. Yamada, Y. Ohshiro and T. Agawa, Bull. Chem. Soc. Jpn., 1982, 55, 909.

40 X. Zhang, H. Liu, X. Hu, G. Tang, J. Zhu and Y. Zhao, Org. Lett., 2011, 13, 3478.

41 A. K. Chatterjee, T.-L. Choi and R. H. Grubbs, Synlett, 2001, 1034.

42 L.-B. Han, C.-Q. Zhao, S. Onozawa, M. Goto and M. Tanaka, J. Am. Chem. Soc., 2002, 124, 3842.

43 L.-B. Han, C. Zhang, H. Yazawa and S. Shimada, J. Am. Chem. Soc., 2004, 126, 5080.

44 M. Niu, H. Fu, Y. Jiang and Y. Zhao, Chem. Commun., 2007, 272.

45 S. K. Nune and M. Tanaka, Chem. Commun., 2007, 2858.

46 V. P. Ananikov, L. L. Khemchyan, I. P. Beletskaya and Z. A. Starikova, Adv. Synth. Catal., 2010, 352, 2979.

47 G. Evano, A.-C. Gaumont, C. Alayrac, I. E. Wrona, J. R. Giguere, O. Delacroix, A. Bayle, K. Jouvin,
C. Theunissen, J. Gatignol and A. C. Silvanus, Tetrahedron, 2014, 70, 1529.

48 I. G. Trostyanskaya and I. P. Beletskaya, Tetrahedron, 2014, 70, 2556.

49 L.-B. Han and M. Tanaka, J. Am. Chem. Soc., 1996, 118, 1571.

50 L. Liu, Y. Wu, Z. Wang, J. Zhu and Y. Zhao, J. Org. Chem., 2014, 79, 6816.

51 Q. Gui, L. Hu, X. Chen, J. Liu and Z. Tan, Chem. Commun., 2015, 51, 13922.

52 J.-W. Yuan, L.-R. Yang, P. Mao and L.-B. Qu, $R S C A d v .$, 2016, 6, 87058 .

53 I. Pergament and M. Srebnik, Org. Lett., 2001, 3, 217.

54 Y. Kobayashi and A. D. William, Org. Lett., 2002, 4, 4241.

55 G. W. Kabalka and S. K. Guchhait, Org. Lett., 2003, 5, 729.

56 G. W. Kabalka, S. K. Guchhait and A. Naravane, Tetrahedron Lett., 2004, 45, 4685.

57 Y. Kobayashi and A. D. William, Adv. Synth. Catal., 2004, 346, 1749.

58 R. Zhuang, J. Xu, Z. Cai, G. Tang, M. Fang and Y. Zhao, Org. Lett., 2011, 13, 2110.

59 X. Mi, M. Huang, H. Guo and Y. Wu, Tetrahedron, 2013, 69, 5123.

60 A. Burini, S. Cacchi, P. Pace and B. R. Pietroni, Synlett, 1995, 677.

61 Y. Na, S. Park, S. B. Han, H. Han, S. Ko and S. Chang, J. Am. Chem. Soc., 2004, 126, 250.

62 L. K. Hwang, Y. Na, J. Lee, Y. Do and S. Chang, Angew. Chem., Int. Ed., 2005, 44, 6166.

63 W. Al-Maksoud, J. Mesnager, F. Jaber, C. Pinel and L. Djakovitch, J. Organomet. Chem., 2009, 694, 3222.

64 J. Tarabay, W. Al-Maksoud, F. Jaber, C. Pinel, S. Prakash and L. Djakovitch, Appl. Catal., A, 2010, 388, 124.

65 H. Brunner, N. Le Cousturier de Courcy and J.-P. Genet, Synlett, 2000, 201.

66 N. N. Demik, M. M. Kabachnij, Z. S. Novikova and I. P. Beletskaya, Zh. Org. Khim., 1995, 31, 64.

67 E. Levin, E. Ivry, C. E. Diesendruck and N. G. Lemcoff, Chem. Rev., 2015, 115, 4607.

68 B. Li and P. H. Dixneuf, Chem. Soc. Rev., 2013, 42, 5744. 69 M.-O. Simon and C.-J. Li, Chem. Soc. Rev., 2012, 41, 1415.

70 R. N. Butler and A. G. Coyne, Chem. Rev., 2010, 110, 6302.

71 K. H. Shaughnessy, Chem. Rev., 2009, 109, 643.

72 I. T. Horváth, Green Chem., 2008, 10, 1024.

73 C.-J. Li and B. M. Trost, Proc. Natl. Acad. Sci. U. S. A., 2008, 105, 13197.

74 S. Liu and J. Xiao, J. Mol. Catal. A: Chem., 2007, 270, 1.

75 D. Dallinger and C. O. Kappe, Chem. Rev., 2007, 107, 2563.

76 I. T. Horváth and P. T. Anastas, Chem. Rev., 2007, 107, 2167.

77 C.-J. Li and L. Chen, Chem. Soc. Rev., 2006, 35, 68.

78 C.-J. Li, Chem. Rev., 2005, 105, 3095.

79 N. E. Leadbeater, Chem. Commun., 2005, 2881.

80 R. N. Butler and A. G. Coyne, Org. Biomol. Chem., 2016, 14, 9945.

81 K. Piradashvili, E. M. Alexandrino, F. R. Wurm and K. Landfester, Chem. Rev., 2016, 116, 2141.

82 M. B. Gawande, V. B. D. Bonifácio, R. Luque, P. S. Branco and R. S. Varma, Chem. Soc. Rev., 2013, 42, 5522. 
83 N. Mase and C. F. Barbas III, Org. Biomol. Chem., 2010, 8, 4043.

84 A. Chanda and V. V. Fokin, Chem. Rev., 2009, 109, 725.

85 J. Zhao, P. Li, X. Li, C. Xia and F. Li, Chem. Commun., 2016, 52, 3661.

86 L.-L. Mao, A.-X. Zhou, N. Liu and S.-D. Yang, Synlett, 2014, 2727.

87 K. Murakami, H. Yorimitsu and K. Oshima, Org. Lett., 2009, 11, 2373.

88 D. Alves, R. F. Schumacher, R. Brandão, C. W. Nogueira and G. Zeni, Synlett, 2006, 1035.

89 I. Pergament and M. Srebnik, Tetrahedron Lett., 2001, 42, 8059.
90 K. V. Sajna, V. Srinivas and K. C. K. Swamy, Adv. Synth. Catal., 2010, 352, 3069.

91 D. S. Ryabukhin and A. V. Vasilyev, Mendeleev Commun., 2016, 26, 500.

92 W.-T. Liao, X.-J. Yang, Y.-Y. Tseng, C.-C. Wu, L.-J. Liu and F.-Y. Tsai, Asian J. Org. Chem., 2015, 4, 1112.

93 S.-N. Chen, W.-Y. Wu and F.-Y. Tsai, Tetrahedron, 2008, 64, 8164.

94 D. Xu, C. Lu and W. Chen, Tetrahedron, 2012, 68, 1466.

95 P. Fourgeaud, C. Midrier, J.-P. Vors, J.-N. Volle, J.-L. Pirat and D. Virieux, Tetrahedron, 2010, 66, 758. 